\title{
Operational optimisation of a tailings storage facility based on statistical analysis of historical monitoring records
}

\author{
I Ezama SRK Consulting, Argentina \\ S Pastine SRK Consulting, Argentina \\ J Pinheiro AngloGold Ashanti, South Africa
}

\begin{abstract}
Operational control and trigger action response plans for tailings storage facilities (TSFs) routinely measure a number of operational aspects to assess risk and ensure the TSF does not exceed certain design considerations. Measurements that are routinely used for this purpose include topographical surveys and beacon settlements, density and moisture measurements, and discharge characteristics, among others.

A statistical analysis of the cumulative historical operational datasets from a TSF allows improved knowledge of the level of variability of the considered parameters, and potentially enhances risk-based decision-making by increasing the understanding of uncertainties and the potential for expected deviations during operations (ICMM 2021). The inclusion of a probabilistic dataset in the design inputs allows a performance-based approach to managing a TSF, considering a series of scenarios defined by performance objectives, determining key factors to identify them in a timely manner, and incorporating effective corrective or 'failure' control measurements, that can be improved with sequential forecasts of the TSF behaviour.

This approach was undertaken to optimise the deposition strategy of the Cerro Vanguardia TSF and expand its life-of-mine (LOM), allowing for tighter construction planning and deferral of construction by several years. This had considerable benefits during the current COVID-19 contingency. Statistical analysis of ongoing operational monitoring data was adequately incorporated into operational design optimisation and to select an adequate level of risk tolerance based on an 'as low as reasonably practical' (ALARP) perspective. Performance-based scenarios were identified and plans for timely decision-making were established to forecast reasonable economical/financial planning, and a probability-based events selection to trigger timely operational adjustments.
\end{abstract}

Keywords: tailings storage facility, tailings beach, deposition strategy, operational design, probabilistic risk-based approach

\section{Introduction}

Cerro Vanguardia S.A. (CVSA) is an AngloGold Ashanti owned gold-silver mine located in Santa Cruz, Argentina, $180 \mathrm{~km}$ west of Puerto Deseado. CVSA has been operational for over 20 years, following a gold vein deposit by developing a series of longitudinal pits and underground operations. A single tailings storage facility (TSF) has been in operation since the commissioning of the process.

The CVSA TSF was originally designed following the best available practices at the time. Subsequent raises incorporated new guidelines as they became available, with the last raise designed to ANCOLD (2012) guidelines. The CVSA TSF was operated for a considerable period of time ( 20 years) following stringent operational and control practices. While tight controls were implemented to avoid potential risks, and maintain a low risk profile, no major use of the historical monitoring database was undertaken.

During the development and design of the seventh wall raise, a possibility to increase the potentially usable storage capacity within the basing was identified. Preliminary estimation of available capacity due to favourable beach angles (more favourable than considered in the original design), along with expansion of 
the active area following successive downstream expansions of the dam, indicated that the construction of the wall raise could potentially be deferred by $\sim 2$ years. For effective use of the potential capacity, changes in deposition strategy were required.

To move the concept into a level of detail that would allow decision-making, the following aspects were raised for consideration:

- Are there viable (economically and operationally) and efficient ways to turn the potential storage capacity into effective storage capacity?

- How confident are we on the considered parameters for the assessment of the alternatives?

- What are the risks of not achieving the expected assumptions?

- What other external risks are to be considered in our planning?

- Can an adequate monitoring strategy allow mitigation of these risks?

From a number of alternatives identified for the efficient use of the potential storage capacity, sequential extension of the spigoting system into the TSF basin was preferred and developed. In developing this option further, limitations to this strategy were set based on the limited availability of the in-house construction team, to ensure that the level of construction requirements would not interfere with the day-to-day mine operation requirements. Spigot extensions were therefore restricted to every 2-3 months, and complex working conditions were avoided by preventing extensions too far into the basin to avoid the soft beaches (and avoiding excessive rates of rise in future work areas).

Along with these boundary limits, objectives to develop the works were agreed with the involved in-house stakeholders to manage uncertainty, allow for risk-based decision-making, and to mitigate any potential risks through consistent operational follow-up. This objective can be synthetised as:

1. Undertake the necessary assessments to allow the mine personnel making a decision regarding a potential change in operational strategy to sufficiently understand the uncertainties and risks.

2. Develop the necessary engineering design for the mine to undertake the change in deposition plan, and monitor the implementation of the strategy, thus allowing for timely identification of potential deviations in the plan.

3. To train personnel, follow-up and audit the execution of the enhanced operational strategy, and periodically revisit forecasts to allow operational adjustments in a timely manner.

This paper details the statistical analysis of the key aspect affecting the operational effectiveness of the selected alternative - the probabilistic assessment of the potential efficiency in use of the available capacity performed to facilitate a risk-based decision matrix, and subsequent performance monitoring (and ongoing decision revisioning). Actual performance of the TSF over the period when the change in operational methodology took place is also provided to allow comparison between the design and actual performance.

\section{Statistical analysis of key aspects}

Key aspects affecting the effectiveness in using potentially available capacity within the TSF were related to:

- Beach angle.

- Tailings density.

- Water storage.

All three aspects were set in the initial design ( 20 years previously), and no performance concerns were identified during the operation of the TSF. That is, the deposition plans were consistent with operations and trigger action response plans (TARPs) were consistently not exceeded during the life of the operation. 
However, in performing a material change to the operational design, and to take advantage of the data collected over the extensive TSF operational period, a statistical analysis and correlation of the different parameters over time was undertaken. CVSA's historical monitoring database, while expanded over time with technology advancements, generally maintained good quality over the operational period. Quality of the statistical data could be tested using resampling methodologies for accuracy measurements of the dataset, such as bootstrapping (Efron 1993).

\subsection{Characterisation of rainfall events}

Cerro Vanguardia mine is located in the cold, arid region of Patagonia. The average annual rainfall is highly variable with an average annual precipitation of $190 \mathrm{~mm}$ per year, and wet and dry years varying between 413 and $61 \mathrm{~mm}$ in successive years (in 1997 and 1998 respectively). Although the winter is wetter than the rest of the year, rainfall events are well distributed over the year with a small number of storm events occurring per month. The onsite mean annual evaporation is $1,248 \mathrm{~mm}$ - approximately six times greater than the mean annual precipitation.

To develop a more efficient use of the available space, a good understanding of water storage needs would become a critical aspect (i.e. consuming the available space with tailings, would imply a direct reduction in the spare volume available for water storage). A better assessment of uncertainties in water storage capacity requirements (i.e. minimise requirements for excessively conservative approaches) would benefit the capacity for tailings storage.

The original TSF design was based on national meteorological agency (Instituto Nacional de Tecnología Agropecuaria 2020) isohyets for the area, with limited (conservative) estimations in the mine location area. Incorporation of a probabilistic approach based on the expansion of the rainfall dataset over the operating period has improved understanding of uncertainties in water storage capacity needs (i.e. minimise requirements for excessively conservative approaches), and provided a better understanding of the risks (particularly of the probability of occurrence), and establishment of TARPs needed to maintain a safe operation.

A probabilistic reassessment of the depth of rainfall events was performed with the available data and an intensity-frequency curve was obtained. Figure 1 presents the curve of rainfall depth as a function of the return period for the CVSA TSF.

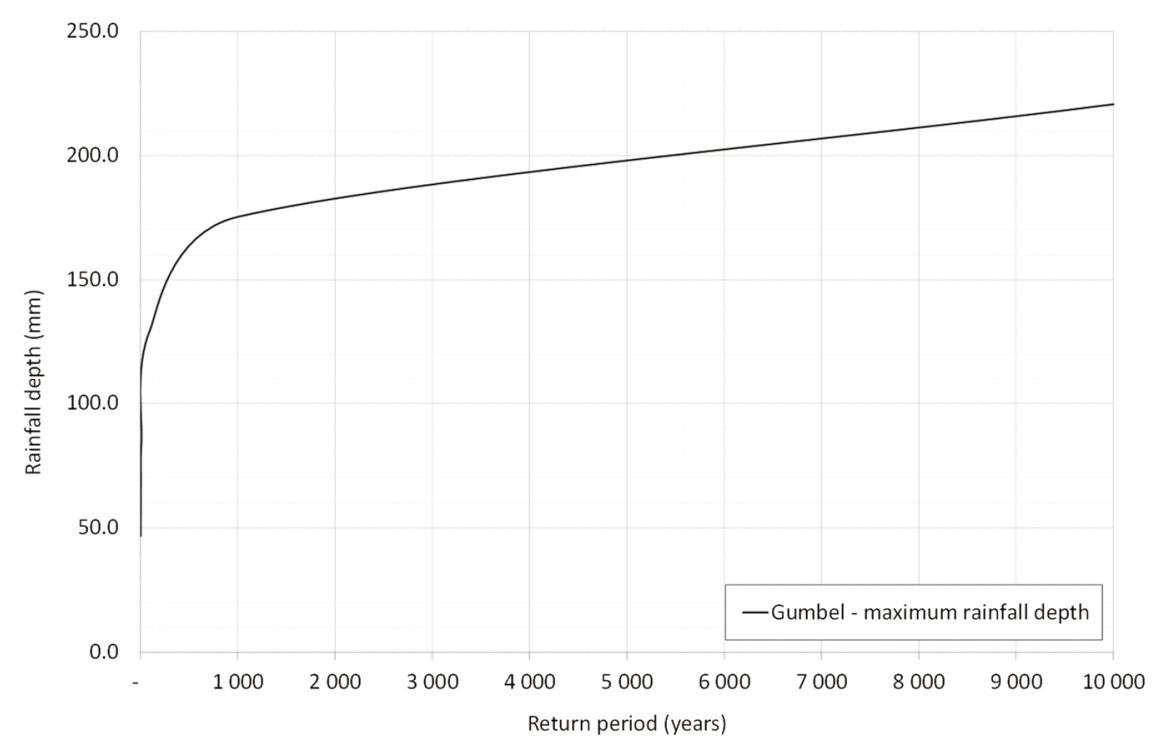

Figure 1 Rainfall depth versus return period 


\subsection{Beach angle}

In previous designs, constant beach slopes between 0.5 and $1.0 \%$ were considered to estimate storage capacity. Available topographical surveys (particularly drone surveys) allow improved tailings beach characterisations. While average tailings beach slopes were found to be consistent with the initial assessments (i.e. average beach slopes of $0.85 \%$ were estimated from topographical surveys), considerable variations in the beach angle along the length of the beach were identified.

Statistical analysis of the beach slope angle along the tailings deposit provided a better characterisation of the beach shape and its potential variance. The main discharge path lines were identified and used to estimate the beach slope angle along the beach (Figure 2).

Values of the beach slope along the beach (starting at the deposition points) were plotted and grouped by distance from the discharge point and path (Figure 3). Anomalies (i.e. points falling on natural terrain or the embankment, and in the pond area) were removed. A normal distribution was found to fit the distribution of results for each given distance from the discharge point.

Finally, the trendline for the average beach slope angles, and its standard deviation (SD) along the path (as exponential functions) were estimated (Figure 4), and theoretical beach profiles (i.e. relative to the discharge point) were developed for use in the storage capacity assessment (Figure 5).

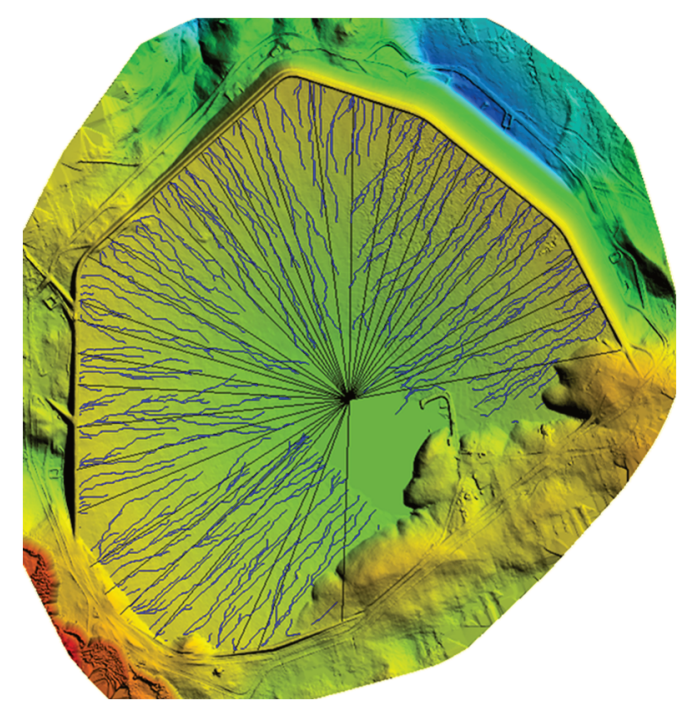

Figure 2 Main tailings discharge paths over the tailings beach (blue) and lines used to calculate beach slope angles (black)

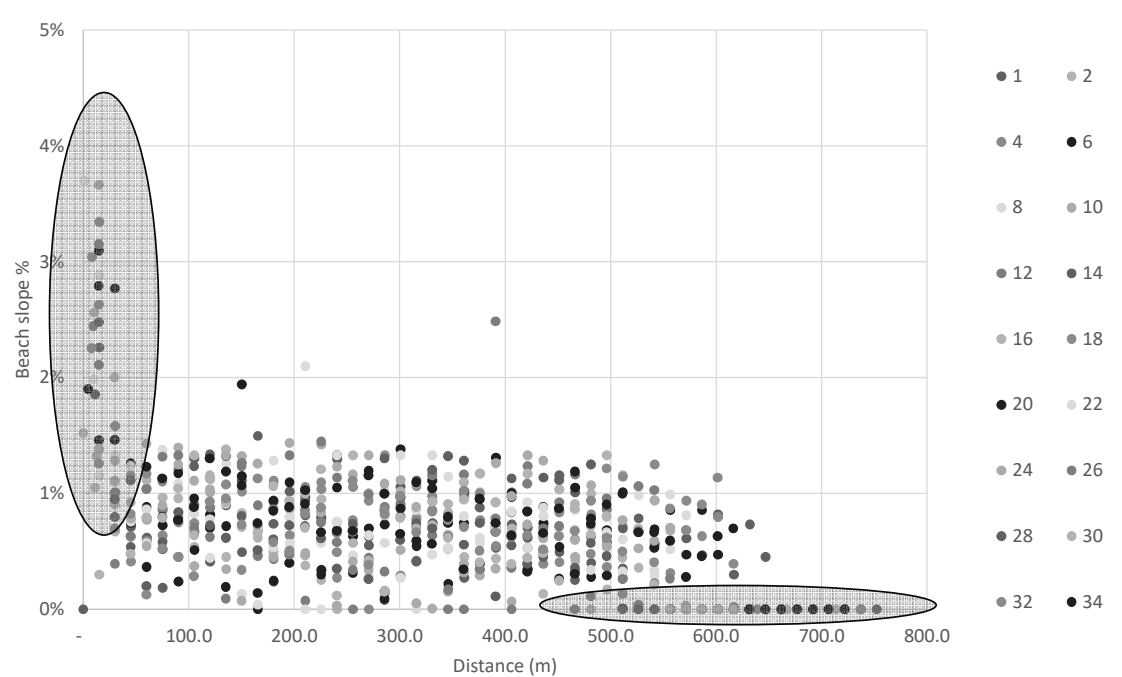

Figure 3 Tailings beach slope angles along the discharge paths before filtering anomalies 


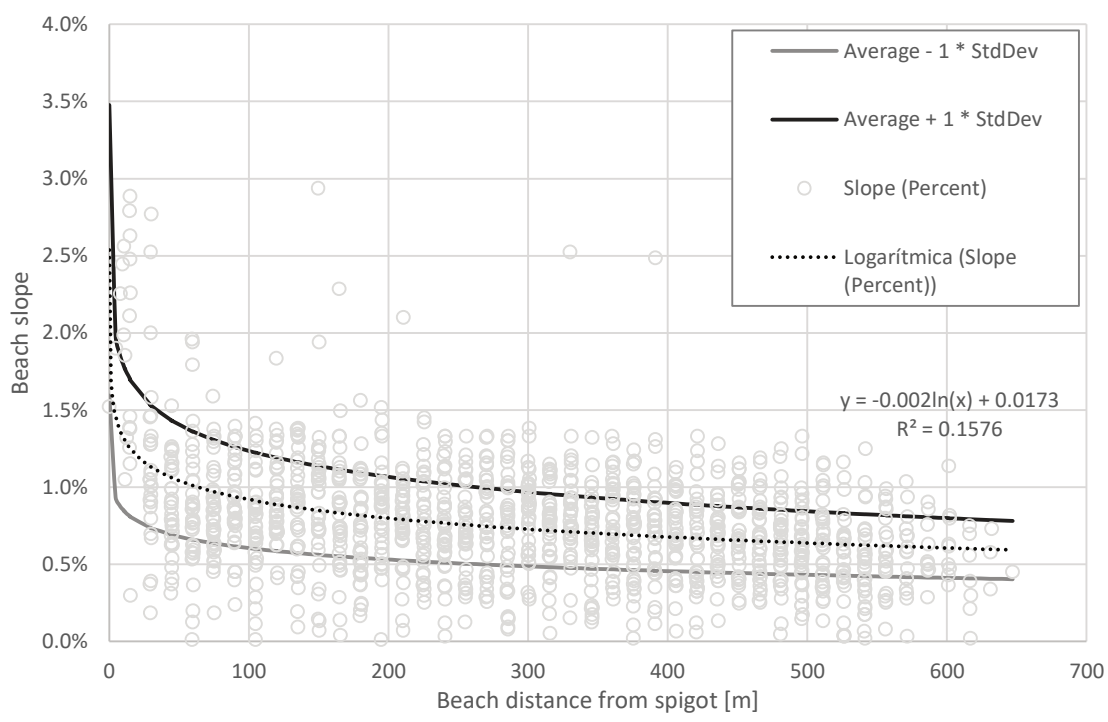

Figure 4 Tailings beach slope angles along the discharge paths

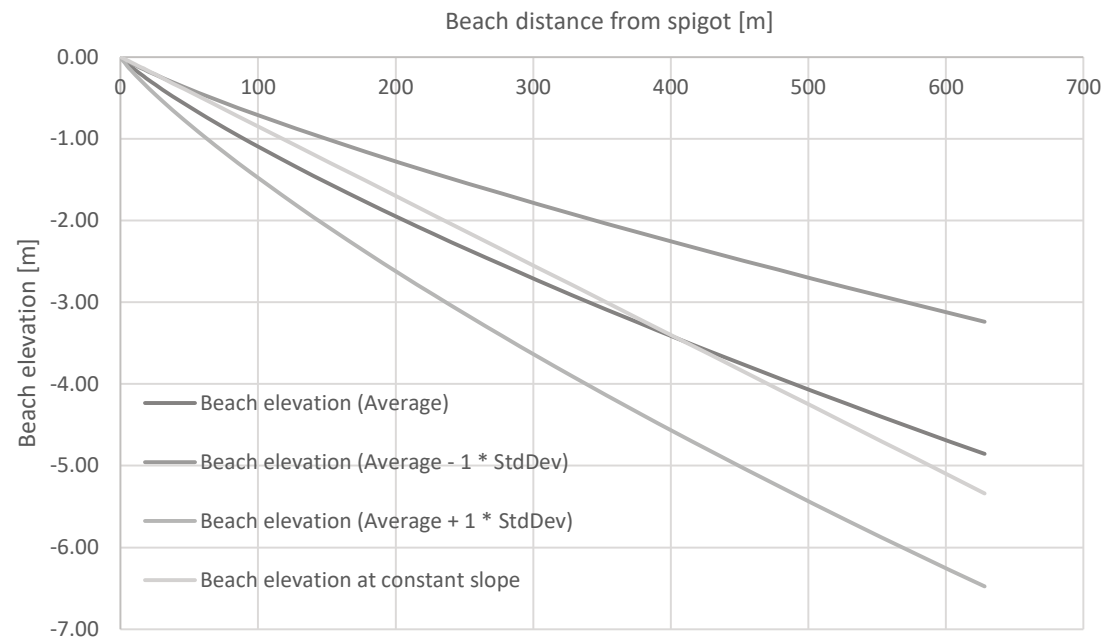

Figure 5 Theoretical tailings beach elevation along the discharge paths for different slopes

\subsection{Tailings density}

Tailings are deposited at a range of solids content (between 45 and $50 \%$ by mass) and have a mostly constant specific gravity (SG) of $\sim 2.7$.

To assess the storage capacity, a statistical analysis of the available geotechnical investigation data was undertaken. Tailings density ranges were characterised based on the available geotechnical samples from the geotechnical investigation, assuming the average density plus/minus one SD to represent the variability (i.e. $\sim 84 \%$ probability of passing the minimum value, assuming normal distribution of the sample). Two variability scenarios were identified, namely:

- Full LOM historical densities: $14.9 \pm 1.0 \mathrm{kN} / \mathrm{m}^{3}$ (associated to an $8 \mathrm{~m}$ profile; probably representing 8-10 years' deposition history).

- Short-term historical densities: $15.7 \pm 0.4 \mathrm{kN} / \mathrm{m}^{3}$ (representing the last two years of deposition, when a beach slope angle increase took place and related to the most recent operational practices).

This difference between the short-term and long-term historical densities was associated with improvements in water recovery (and solids content at deposition) in the same period. For the period of analysis (i.e. the period of two years in which the operational change occurred), no particular variation in the incoming ore 
characteristics or processing aspects were found. Therefore, the short-term density range was considered more realistic for the analysis. Long-term data was only considered for sensitivity.

Finally, a positive covariance (COV) between the tailings beach angle and the dry density (i.e. an increase in the tailings beach angle associated with an increase in the tailings density), was identified based on the statistical data. To reflect this statistical association between the tailings beach angle and the dry density, the tailings density ranges were associated with the densities assuming a linear relation (i.e. COV(beach angle, dry density) $=1$ ).

\section{Probabilistic capacity estimation and performance-based decision matrix}

For the capacity assessment, the scenario considered was a tailings discharge from a single spigot at a given time, and changing in time over 34 locations. Five successive spigot extensions into the tailings beach (perpendicular to the embankment) were considered, with varying lengths. Figure 6 presents a layout of the discharge points at the end of the operational change.

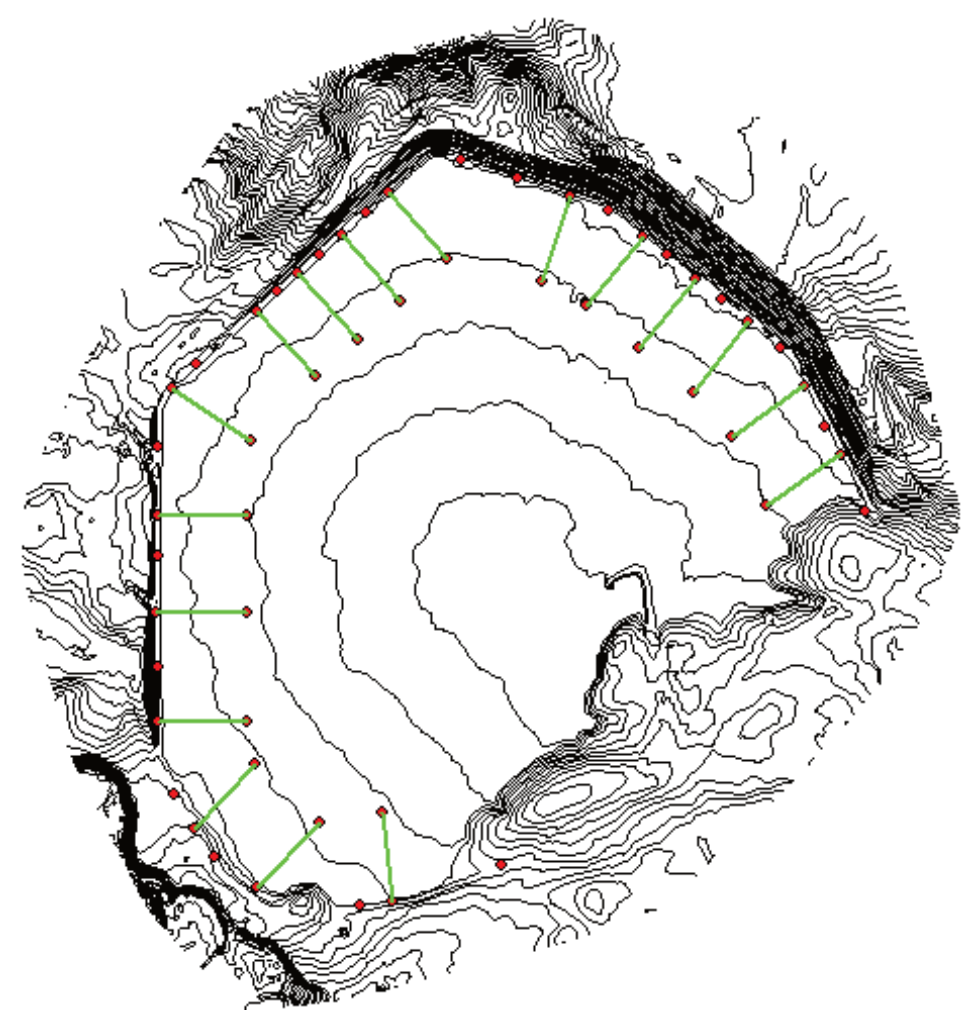

Figure 6 Layout of the discharge points within the TSF at the end of the operational change

Four beach development profiles were considered for the study:

- Base case: Average beach slope angles along the discharge path (50th percentile).

- Favourable case: Average minus one SD of the beach slope angles along the discharge path (16th percentile).

- Worst case: Average plus one SD of the beach slope angles along the discharge path (84th percentile).

- Original design approach case: Constant $0.85 \%$ slope.

Volumetric storage capacity, time availability and the estimated date at which storage capacity would be fulfilled were estimated for each case. Time availability incorporated associated densities, and the estimated end date started from May 2019. A summary of the model outcomes is presented in Table 1. 
Table 1 Storage capacity, time availability and estimated end date

\begin{tabular}{lllllll}
\hline Case & \multicolumn{2}{c}{ Storage capacity } & \multicolumn{2}{l}{ Time availability } & \multicolumn{2}{l}{ Estimated end date } \\
& Total $\left(\mathbf{m}^{3}\right)$ & $\begin{array}{l}\Delta \text { Total } \\
(\%)\end{array}$ & $\begin{array}{l}\text { Total } \\
(\text { days })\end{array}$ & $\begin{array}{l}\Delta \text { Total } \\
(\%)\end{array}$ & $\begin{array}{l}\text { End date } \\
\text { Exceedance } \\
\text { probability } \\
(\%)\end{array}$ \\
\hline Base case & $2,037,782$ & - & 941 & - & Dec 2021 & $\sim 50 \%$ \\
Favourable case & $2,280,341$ & $12 \%$ & 1,026 & $9 \%$ & Feb 2022 & $\sim 16 \%$ \\
Worst case & $1,862,918$ & $-9 \%$ & 882 & $-6 \%$ & Oct 2021 & $\sim 84 \%$ \\
$\begin{array}{l}\text { Original design } \\
\text { approach case }\end{array}$ & $2,189,379$ & $7 \%$ & 902 & $-4 \%$ & Oct 2021 & - \\
\hline
\end{tabular}

In order to safely plan the operational design and the wall raise construction phases, the 84th percentile results were adopted to reduce the potential of not achieving the due date because of construction needs.

Along with planning, periodic monitoring of the operation was implemented to assess the behaviour of the ongoing operational results and to identify any potential changes in the capacity estimates. Along with the monitoring of each of the directly measured aspects, combined estimates of the aspects were developed to allow for a more 'visible' assessment of the overall behaviour of the operation. Figure 7 presents a typical outcome of this combined estimate. In this way, the decision-making mechanism was maintained (i.e. manoeuvring capacity to apply timely solutions to unexpected behaviours in operation, and minimise negative impacts) providing flexibility and adaptability to the design.

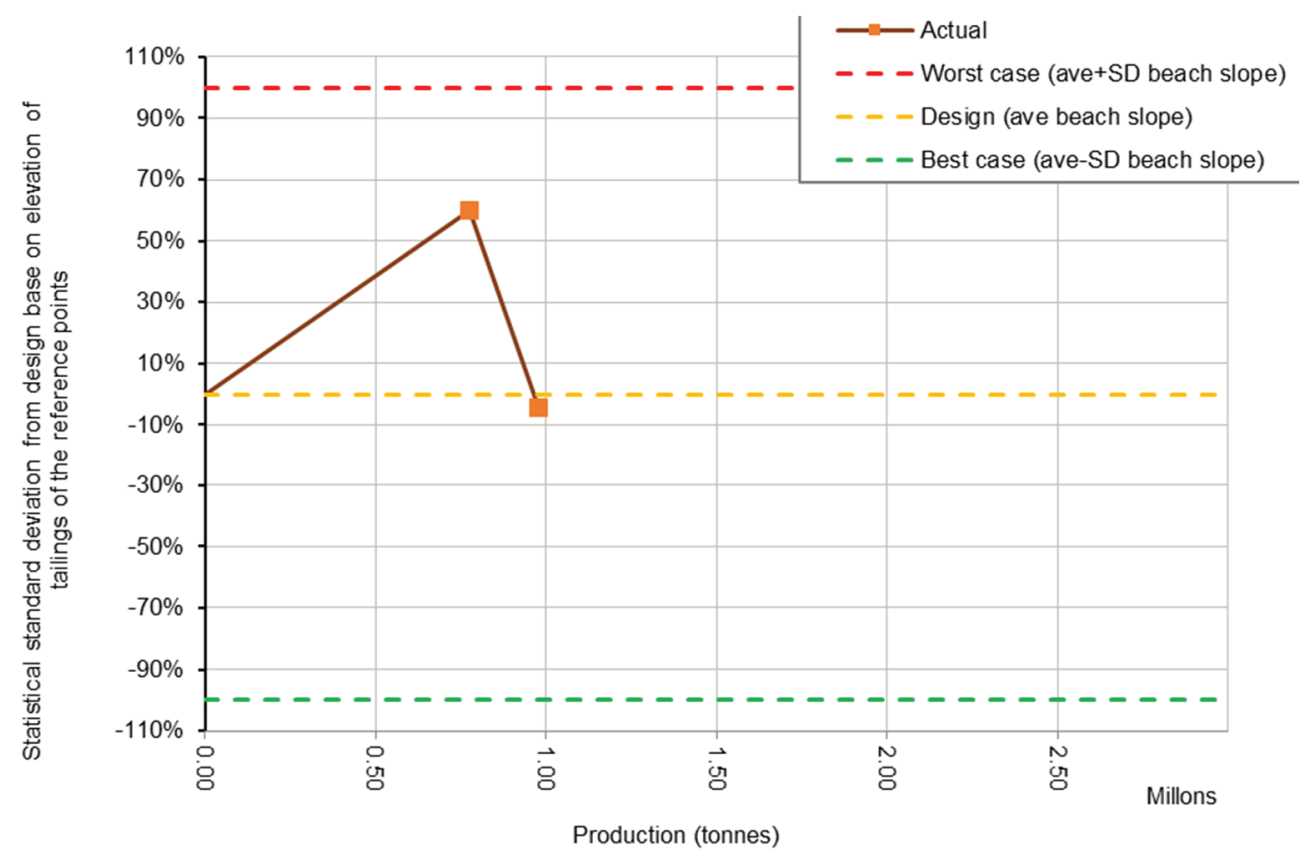

Figure 7 Overall SD of the tailings surface versus production

\section{$4 \quad$ Actual performance}

As part of the surveillance activities, the beach slope was periodically monitored over the period of implementing the operational enhancement. Periodic revisits to the parameters considered were also undertaken as more information became available. Beach profiles (as the most sensitive of the influencing parameters) are presented in Figure 8. Except for the October 2020 survey (where some deviations in the topography were identified) all beach profiles lay between the average and best cases (i.e. between the mean and the mean minus SD range), in line with the adopted case for the operational design. 

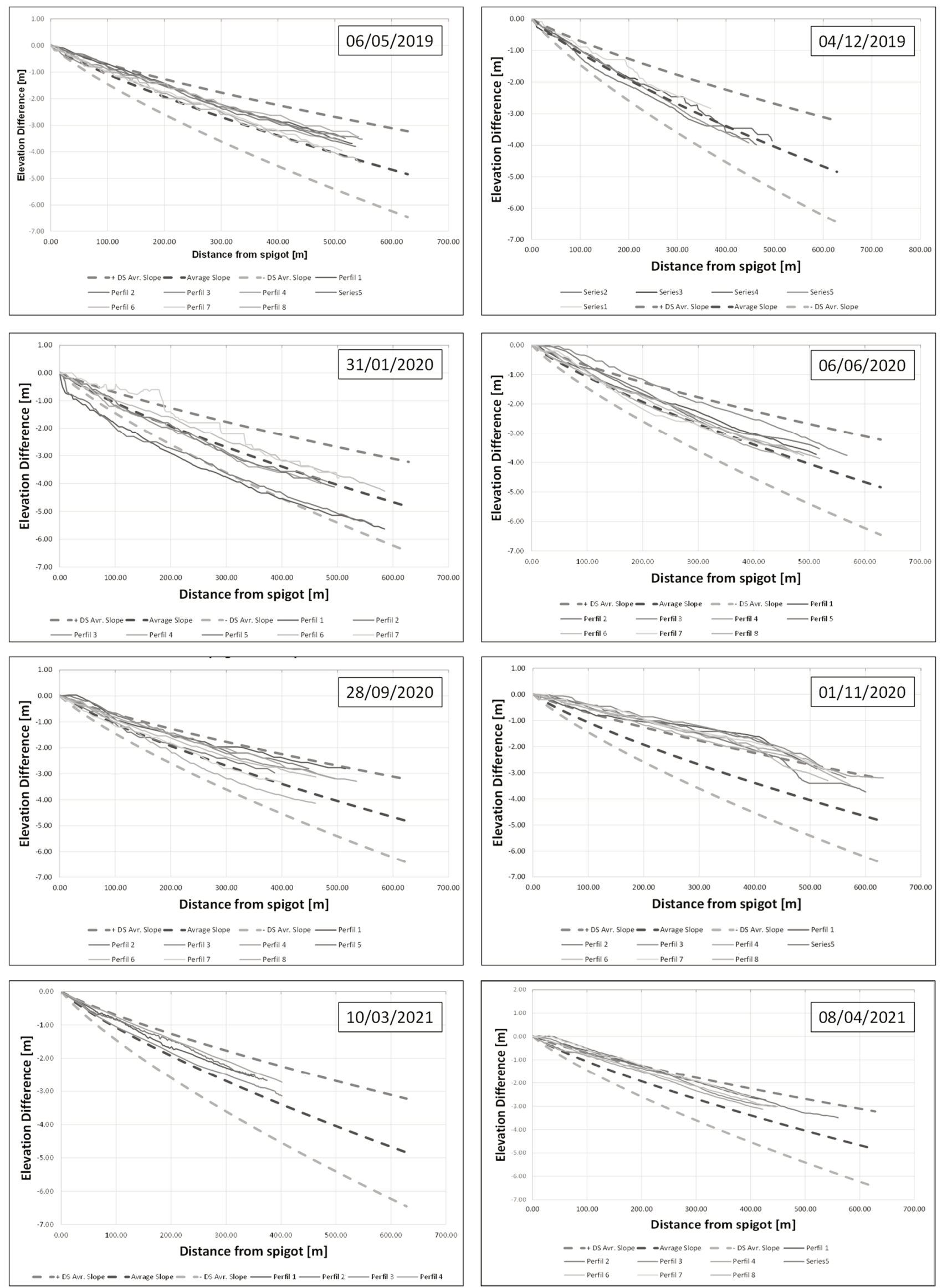

Figure 8 Beach profiles obtained from three-monthly tailings surveys 
Based on the actual onsite deposition, this modelling has proved to be accurate and benefited the operations as additional delays caused by the COVID-19 restrictions and contractor delays resulted on the original construction program shifting out by an additional three months. Therefore, maintaining a decision-making mechanism (i.e. manoeuvring capacity to apply timely solutions to unexpected behaviours in operation, and minimise negative impacts) and providing flexibility and adaptability to the design proved to be the correct decision.

\section{Conclusion}

Based on the optimisation work carried out at the CVSA TSF we can conclude that:

- Good quality data collection during operations can be of great value in identifying improvements to be undertaken.

- Periodical statistical analysis of incoming data, and statistical correlations are of great use in achieving a better understanding of our operations.

- Data quality can be easily tested using resampling methodologies for accuracy measurements of the dataset, such as bootstrapping (Efron 1993), allowing for a rapid understanding of the level of uncertainty in our database, and identifying when the level of confidence of our dataset is 'good enough' to start handling a probabilistic approach.

- Risk tolerance and decision-making schedules can be integrated to enhance operations, with the potential for considerable reductions in costs and risk.

Finally, a key aspect of this success was a well-timed and executed planning schedule by a competent operational team, that did not affect the metallurgical operations, and at the same time allowed for the execution of the adjusted deposition strategy, thus optimising the available capacity of the TSF.

\section{Acknowledgement}

The authors acknowledge the CVSA metallurgy and TSF operational teams for their commitment and continuous support.

\section{References}

Australian National Committee on Large Dams 2012, Guidelines on Tailings Dams - Planning, Design, Construction, Operation and Closure, Australian National Committee on Large Dams, Hobart.

Efron, B 1993, An Introduction to the Bootstrap, Chapman \& Hall, Boca Raton.

Instituto Nacional de Tecnología Agropecuaria 2020, viewed 12 August 2021, https://inta.gob.ar/noticias/se-genero-una-base-dedatos-de-precipitacion-para-la-provincia-de-santa-cruz?fbclid=IwAR1PstESbleW8hoFQxNZ-2Kp4ktba3ECc4Ru43M84fRVkU0 q5qgFor46Fgs/

International Council on Mining \& Metals 2021, Tailings Management - Good Practice Guide, International Council on Mining \& Metals, London, viewed 10 August 2021, https://www.icmm.com/website/publications/pdfs/environmental-stewardship/ 2021/guidance_tailings-management.pdf 
Operational optimisation of a tailings storage facility based on statistical analysis of historical monitoring records 